\title{
Recovery and prediction of postoperative muscle power - is it still a problem?
}

\author{
Martin Zoremba ${ }^{1,3^{*}}$, Dennis Kornmann ${ }^{1}$, Benjamin Vojnar ${ }^{1}$, Rene Burchard ${ }^{3}$, Thomas Wiesmann ${ }^{1}$, Hinnerk Wulf \\ and Thomas Kratz ${ }^{1,2}$
}

\begin{abstract}
Background: In the postoperative period, immediate recovery of muscular power is essential for patient safety, but this can be affected by anaesthetic drugs, opioids and neuromuscular blocking agents (NMBA). In this cohort study, we evaluated anaesthetic and patient-related factors contributing to reduced postoperative muscle power and pulse oximetric saturation.

Methods: We prospectively observed 615 patients scheduled for minor surgery. Premedication, general anaesthesia and respiratory settings were standardized according to standard operating procedures (SOP). If NMBAs were administered, neuromuscular monitoring was applied to establish a Train of four (TOF)-Ratio of $>0.9$ before extubation. After achieving a modified fast track score $>10$ at 4 time points up to $2 \mathrm{~h}$ postoperatively, we measured pulse oximetric saturation and also static and dynamic muscle power, using a high precision digital force gauge. Loss of muscle power in relation to the individual preoperative baseline value was analysed in relation to patient and anaesthesia-related factors using the T-test, simple and multiple stepwise regression analysis.
\end{abstract}

Results: Despite having achieved a TOF ratio of $>0.9$ a decrease in postoperative muscle power was detectable in most patients and correlated with reduced postoperative pulse oximetric saturation. Independent contributing factors were use of neuromuscular blocking agents $(p<0.001)$, female gender $(p=0.001)$, TIVA $(p=0.018)$ and duration of anaesthesia $>120 \min (p=0.019)$.

Conclusion: Significant loss of muscle power and reduced pulse oximetric saturation are often present despite a TOFRatio $>0.9$. Gender differences are also significant. A modified fast track score $>10$ failed to predict recovery of muscle power in most patients.

Trial registration: German Clinical Trial Register DRKS-ID DRKS00006032; Registered: 2014/04/03

Keywords: Muscle power, Nmba, Pulse oximetric saturation

\section{Background}

Use of neuromuscular blocking agents (NMBA) is associated with postoperative respiratory complications $[1,2]$; they have a significant effect on neuromuscular recovery [3]. Even a small delay in recovery of pharyngeal muscular tone can induce upper airway collapse as well as microaspiration leading to respiratory dysfunction or pneumonia $[4,5]$. Thus perioperative (quantitative) neuromuscular monitoring, in particular acceleromyography, is essential to

\footnotetext{
* Correspondence: m.zoremba@kreisklinikum-siegen.de

'Department of Anaesthesia and Intensive Care Medicine, University of

Marburg, Baldinger Strasse, D-35033 Marburg, Germany

${ }^{3}$ Department of Anaesthesia, Intensive Care Medicine and Pain therapy,

Kreisklinikum, Weidenauerstrasse 76, D-57076 Siegen, Germany

Full list of author information is available at the end of the article
}

ensure a TOF-Ratio $>0.9$ before extubation $[6,7]$. Although regarded as the gold standard, it may not be able to detect lesser degrees of neuromuscular block $[8,9]$. Thus postoperative residual neuromuscular blockade (RNMB) cannot be completely excluded by the use of neuromuscular monitoring [10]. Even with intermediate duration of anaesthesia, it can occur after a single dose of NMBA [11]. Other anaesthesia- and patient-related factors can affect postoperative muscle strength and recovery [12-15]. The overall clinical relevance of postoperative muscle strength impairment within the postoperative period is frequently underestimated because the clinical signs of RNMB are not necessarily obvious [16]. Current standards for its detection in association with upper 
airway collapse have been developed in healthy subjects in the absence of other detrimental factors such as sedatives and analgesics $[17,18]$. In this cohort study we evaluated the factors contributing to loss of muscle power in the immediate postoperative period after a TOF-ratio of $\geq 0.9$ had been obtained.

\section{Methods}

Ethics committee approval was obtained (University of Marburg, ref. no. AZ 176/09; German Clinical Trial Register DRKS-ID DRKS00006032). Informed consent was obtained in every patient included. As a result of the study design no written consent was demanded by the Ethics committee. We included 801 adult patients who were scheduled for minor surgery in general anaesthesia into this prospective observational study. They were nursed postoperatively in our post anaesthetic care unit (PACU) between 31st of january, 2010 and 31st of december 2012. In order to display daily routine no randomization was performed. Premedication and general anaesthesia was performed according to our standard operating procedures (SOP). Primary outcomes were defined as lack of postoperative muscle power and the identification of possible independent contributing risk factors. Secondary outcome is the impact of these factors on postoperative pulse oximetric saturation. Patients receiving neostigmine for reversal were excluded.

\section{Patients}

Inclusion criteria were: age $\geq 18$ years, American Society of Anaesthesiologists status (ASA) I-III, minor surgery), general anaesthesia. Minor surgery was defined as elective surgery, superficial surgery procedures, estimated blood loss $<500 \mathrm{ml}$, modest postoperative pain expected, no prone positioning.

Excluded were patients of minor age $(<18$ years), and subjects undergoing thoracoabdominal surgery, as patients who were scheduled for surgery in regional anaesthesia.

\section{General anesthesia}

Twelve hours before surgery, patients received clorazepate $20-40 \mathrm{mg}$ orally. In the anaesthesia induction room, standard monitoring according to Association of Anaesthetists of Great Britain and Ireland (AAGBI) guidelines was established. General anaesthesia was induced according to our SOP using fentanyl $3 \mu \mathrm{g} \mathrm{kg}^{-1}$ and propofol $1.5-2.5 \mathrm{mg} \mathrm{kg}^{-1}$. A single dose of rocuronium (0.5 mg kg ${ }^{-1}$ ideal body weight) was given for tracheal intubation. When laryngeal mask was used, NMBA was avoided. No further neuromuscular blocking agent was given during surgery. All patients were ventilated to maintain an end-tidal $\mathrm{CO}_{2}$ pressure of approximately 4-4.7 $\mathrm{kPa}$. A maximum peak pressure of 30 $\mathrm{cmH}_{2} \mathrm{O}$ was allowed for pressure-controlled ventilation with tidal volumes of $6-7 \mathrm{ml} \mathrm{kg}^{-1}$. The inspiration to expiration ratio was $1: 1.5$ and a positive end expiratory pressure of $5-8 \mathrm{cmH}_{2} \mathrm{O}, 8-10 \mathrm{cmH}_{2} \mathrm{O}$ when Body mass index (BMI) exceeded $35 \mathrm{~kg} \mathrm{~cm}^{-2}$ was applied throughout in all patients, using an adjusted $\mathrm{FiO}_{2}$ of 0.5 during anaesthesia maintenance and $\mathrm{a}_{\mathrm{FiO}_{2}}$ of 1.0 before extubation. To achieve comparable anaesthetic depths, self-adhesive Bispectral Index (BIS) electrode strips (BIS Quattro $^{\text {mw }}$; Aspect Medical Systems, Freising, Germany) were positioned on the forehead as recommended. General anaesthesia was maintained by sevoflurane (0.5$2 \mathrm{Vol} \%)$ or propofol infusion $\left(6-12 \mathrm{mg} \mathrm{kg}^{-1}\right)$ and intermittent bolus application of fentanyl $0.5-2 \mu \mathrm{g} \mathrm{kg}^{-1}$ to maintain BIS within a range of 35-60. According to our standard operating procedures the train of four (TOF) ratio (uncalibrated) was controlled (TOF-Watch ${ }^{\mathrm{Tm}}$, Organon Teknika, Eppelheim Germany) to $>0.90$ before extubation ensured by a member of our research staff team (study nurse/postgraduate). A warming blanket device (Bair Hugger ${ }^{\text {rum }}$, Arizant, Trittau, Germany) was applied during surgery. Each patient received dexamethasone $(4 \mathrm{mg}$ i.v., after induction) and dolasetron (25 mg i.v., $15 \mathrm{~min}$ before extubation) as prophylaxis against nausea and vomiting. When the patients were fully awake, alert and breathing spontaneously, the lungs were extubated on an inspiratory oxygen concentration of $100 \%$. After transport to the PACU, they were nursed in the half sitting head up position for full recovery. Patients, reversed from residual neuromuscular blockade, were not included for further analysis.

\section{Evaluation of fast track score \& postoperative management}

Postoperative surveillance and nursing was according to our local guidelines. No sedatives were administered in the PACU. Research staff members observed and assessed the fast track score according to White and Song [19] after patient arrival at PACU at the fixed time points. PACU time was calculated when a score of 10 or more of 14 was achieved. All patients remained in the PACU until the measurements at $\mathrm{T} 2 \mathrm{~h}$ were completed. Antiemetic drugs were given according to our local guidelines. VAS was evaluated at 15-min intervals. All patients received intravenous (i.v.) non-opioid analgesia (metamizole $15-25 \mathrm{mg} \mathrm{kg}$ $\left.{ }^{-1}\right) 15 \mathrm{~min}$ before the estimated end of surgery. In the PACU, visual analogue scale (VAS) scores were evaluated at 15 -min intervals. Piritramide i.v. was given by the PACU nurses whenever the VAS exceeded 4. After PACU discharge, basic analgesia on the ward was performed as requested with ibuprofen and metamizole oral (nurse-controlled). Overall drug consumption as well as the related VAS scores were recorded within the first 24 hours. 


\section{Muscle power measurements}

As previously described static and dynamic hand muscle power was measured using a high precision digital force gauge (Force gauge FMI-100, Alluris, Freiburg, Germany) in a modified thumb pressure approach [20]. Baseline muscle power measurement was performed at the pre-anaesthetic visit after thorough demonstration of the method. We registered peak thumb pressure as the best of three attempts. In the PACU, measurements were performed as soon as the patient was alert and cooperative (Fast Track score > 10 (T0 h); pain and dyspnoea were assessed during coughing before and, if necessary, after analgesic therapy. All measurements were repeated in the PACU by research staff members at $30 \mathrm{~min}(\mathrm{~T} 0.5 \mathrm{~h}), 1 \mathrm{~h}$ (T1 h) and $2 \mathrm{~h}(\mathrm{~T} 2 \mathrm{~h})$ after PACU arrival.

\section{Pulse oximetry}

Pulse oximetry was standardized. It was measured on 3 different fingers ensuring a stable signal quality and using the best value without any supplemental oxygen. All included patients had a postoperative body temperature $>36^{\circ}$ during PACU stay. Baseline pulse oximetry was performed at the pre-anaesthetic visit and postoperative measurements were made in the PACU by research staff members after a Fast Track score $>10(\mathrm{~T} 0 \mathrm{~h})$ had been achieved at the same time points as above. Oxygen (1-6 L/min) was administered by face mask when pulse oximetric saturation $\left(\mathrm{SpO}_{2}\right)$ values were $<90 \%$.

\section{Statistic analysis}

In order to review all the potential risk factors for reduced postoperative pulse oximetric saturation and muscle power, a systematic review of the literature was performed using the search terms - ('muscle power' OR 'reduced pulse oximetric saturation' AND ('predict' OR 'risk model' OR 'risk factor') - and other combinations of these terms $[1,10,11,15,21-26]$. The following were all included for analysis against the variables postoperative muscle strength and pulse oximetric saturation, and their interaction; NMBA usage, age, gender, BMI, airway method (Larynx mask (LMA)/Intubation (ITN)), premedication, maintenance (balanced anaesthesia/total intravenous anaesthesia - TIVA), anaesthesia duration, neck circumference, postoperative opioid consumption, and fast track score $>10$ within $20 \mathrm{~min}$ in PACU.

Postoperative $\mathrm{SpO}_{2}$ and muscle power were analysed as percentages of baseline. After dichotomization of the continuous data, univariate comparisons between the individual factors and target variables $\left(\mathrm{SpO}_{2} /\right.$ Muscle power) were calculated for each variable at each time point. The Kolmogorov-Smirnov t-test or Mann-Whitney U-tests for non-normally distributed variables was applied for continuous variables. Variables with a two-sided nominal $P$ value of less than 0.2 in either analysis were further investigated jointly with a logistic regression framework. A stepwise mixed logistic regression analysis was used to develop the final prediction models for impaired muscle power or $\mathrm{SpO}_{2}$, respectively. Statistic analysis was realised with JMP 8 for MAC (SAS Institute Inc., Cary, NC).

\section{Results}

Overall, 801 patients were included in our study; their basic biometric and specific perioperative anaesthesia related data was collected by study nurses. Patients

Table 1 Basic cohort data including patients' demographics, peri- and postoperative anaesthetic procedural data and medications (615 patients) T-test/chi-square evaluation of the main study populations (NMBA+/NMBA-)

\begin{tabular}{|c|c|c|c|c|}
\hline & Cohort data $(n=615)$ & $\mathrm{NMBA}+(n=347)$ & NMBA- $(n=268)$ & $p$-Value \\
\hline Gender (M/F) & $278 / 337$ & $185 / 162$ & $93 / 175$ & 0.001 \\
\hline Age & $53 \pm 15$ & $55 \pm 14$ & $50 \pm 16$ & 0.001 \\
\hline BMI & $27.5 \pm 4.9$ & $28 \pm 5.0$ & $26.4 \pm 4.5$ & 0.001 \\
\hline TIVA/Balanced Anaesthesia (n) & $378 / 237$ & $74 / 273$ & $105 / 163$ & 0.001 \\
\hline Premedication (Clorazepat mg) & $27 \pm 12$ & $28 \pm 11$ & $26 \pm 11$ & 0.059 \\
\hline Fentanyl (mg) & $0.44 \pm 0.3$ & $0.49 \pm 0.2$ & $0.36 \pm 0.2$ & 0.001 \\
\hline BIS intraoperative & $39 \pm 7$ & $38 \pm 6$ & $39 \pm 7$ & 0.0141 \\
\hline BIS end & $42 \pm 11$ & $42 \pm 10$ & $43 \pm 11$ & 0.174 \\
\hline Metamizole (mg) & $1.7 \pm 0.5$ & $1.7 \pm 0.5$ & $1.6 \pm 0.4$ & 0.068 \\
\hline Piritramide (mg) & $7.8 \pm 4.5$ & $7.9 \pm 4.0$ & $7.6 \pm 5.0$ & 0.480 \\
\hline Anaesthesia time (min) & $130 \pm 51$ & $139 \pm 43$ & $117 \pm 45$ & 0.001 \\
\hline Fast Track score > 10 PACU (min) & $25 \pm 21$ & $28 \pm 23$ & $22 \pm 16$ & 0.001 \\
\hline $\mathrm{SpO}_{2} \cdot$ pre-OP (\%) & $97.2 \pm 1.5$ & $97.0 \pm 1.5$ & $97.4 \pm 1.4$ & 0.002 \\
\hline
\end{tabular}

Abbreviations: NMBA neuromuscular blocking agents, $M$ male, $F$ female, BMI body mass index, TIVA Total intravenous anaesthesia, BIS Bispectral Index, PACU Post anaesthetic care unit, $\mathrm{SpO}_{2}$ pulse oximetric saturation, pre-OP preoperative

Plus minus value: mean \pm SD 
Table 2 Basic postoperative measurements of muscle power and $\mathrm{SpO}_{2}$ in $\mathrm{PACU}$ (individual percentage of preoperative baseline)

\begin{tabular}{lllll}
\hline & T0 $\mathrm{h}$ & T0.5 $\mathrm{h}$ & $\mathrm{T} 1 \mathrm{~h}$ & $\mathrm{~T} 2 \mathrm{~h}$ \\
\hline Muscle power (\%) $n=615$ & $74.3 \pm 22$ & $82.0 \pm 20$ & $82.4 \pm 20$ & $77.7 \pm 20$ \\
Muscle power + NMBA (\%) $n=347$ & $66.8 \pm 21$ & $77.2 \pm 21$ & $88.5 \pm 18$ & $84.0 \pm 21$ \\
Muscle power -NMBA (\%) $n=268$ & $82.8 \pm 21$ & $87.1 \pm 19$ & $98.4 \pm 3$ & $89.6 \pm 17$ \\
$\mathrm{SpO}_{2}(\%) n=615$ & $97.2 \pm 3$ & $98.0 \pm 3$ & $98.1 \pm 3$ & $98.8 \pm s d 2$ \\
$\mathrm{SpO}_{2}+\mathrm{NMBA}(\%) n=347$ & $96.7 \pm 3$ & $97.6 \pm 3$ & $99.0 \pm 2$ & $99.1 \pm \mathrm{sd} 2$ \\
$\mathrm{SpO}_{2}-\mathrm{NMBA}(\%) n=268$ & $97.9 \pm 3$ & $98.5 \pm 2$ &
\end{tabular}

Abbreviations: PACU Post anaesthetic care unit, $\mathrm{SpO}_{2}$ pulse oximetric saturation, NMBA neuromuscular blocking agents Plus minus value: mean \pm SD, $p$-values displayed in Tables 3 and 6

receiving supplemental regional anaesthesia techniques were excluded. After thorough screening, 615 complete datasets were included for final analysis (Table 1). Overall cohort data exhibit except of TIVA vs balanced anaesthesia no differences in dichotomized data. Detailed evaluation of the main cohort data (+NMBA/-NMBA) indicate differences in distribution within the respective $t$-test an chi-square tests (Table 1 ).

\section{Postoperative muscle power}

Significant reduction of muscle power was detectable postoperatively in most patients (Table 2, Fig. 1). Within
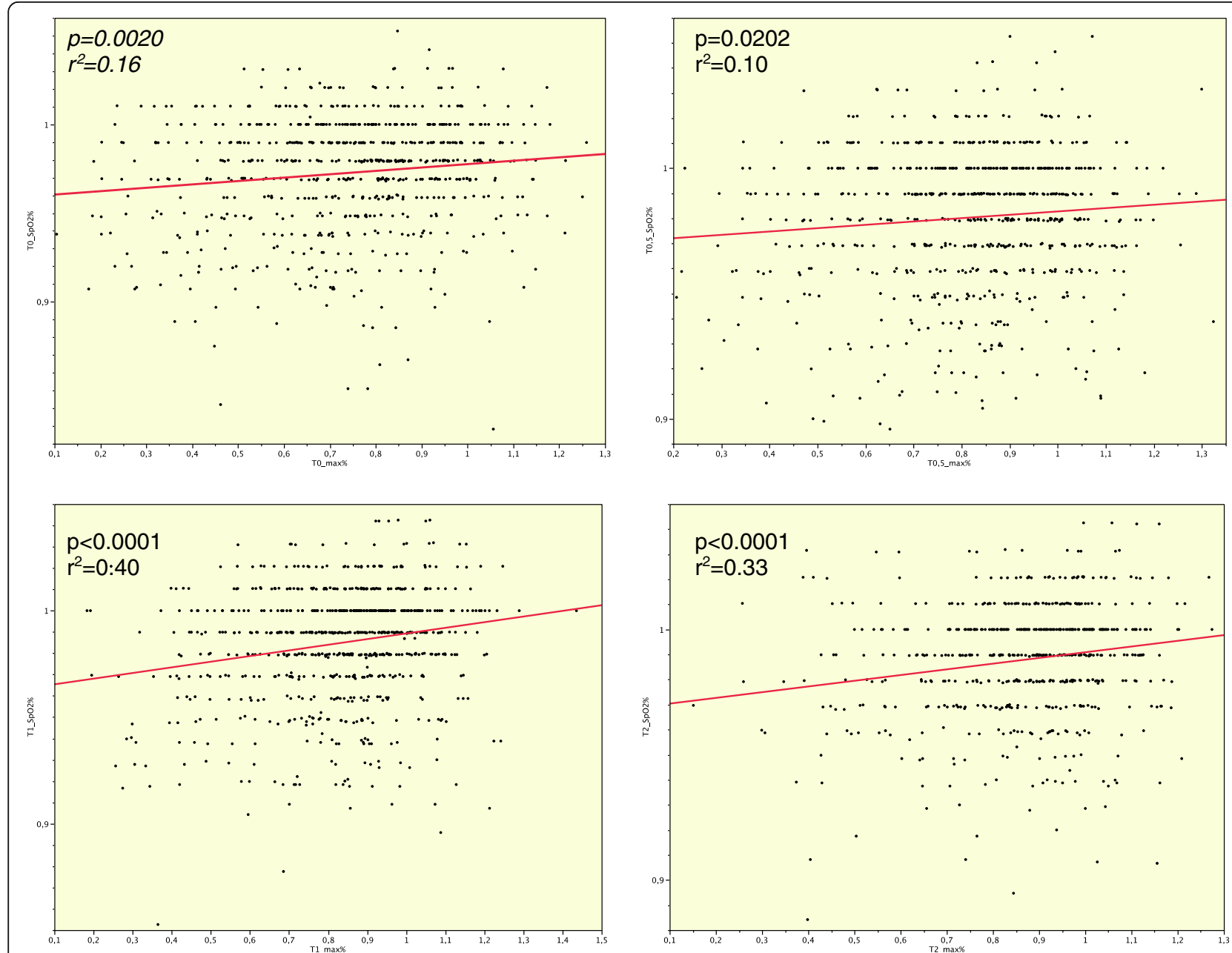

Fig. 1 Muscle power/pulse oximetric saturation. Simple regression analysis: Correlation of pulse oximetric Saturation and muscle power in terms of NMBA usage $(+/-) y$-axis = pulse oximetric saturation (percentage of preoperative baseline) $x$-axis = peak muscle power (percentage of preoperative baseline) 
Table 3 Effects on postoperative muscle power (t-Test, $P$-value)

\begin{tabular}{|c|c|c|c|c|}
\hline & TO h & T0.5 h & $\mathrm{T1} \mathrm{h}$ & T2 h \\
\hline Gender (M/F) & 0.0030 & $<0.0001$ & $<0.0001$ & $<0.0001$ \\
\hline Age $(\geq 55)$ & 0.0412 & n.s. & n.s. & n.s. \\
\hline $\mathrm{BMI}(\geq 30)$ & n.s. & n.s. & n.s. & n.s. \\
\hline NMBA (NMBA+/NMBA-) & $<0.0001$ & $<0.0001$ & $<0.0001$ & $<0.0001$ \\
\hline TIVA/Balanced Anaesthesia & n.s. & 0.0241 & 0.0177 & 0.0135 \\
\hline Clorazepate ( $\geq 20 \mathrm{mg}$ ) & 0.0066 & n.s. & n.s. & n.s. \\
\hline Anaesthesia time( $\geq 120$ min) & 0.0002 & 0.0115 & 0.0116 & 0.0073 \\
\hline Fast Track score in PACU ( $\geq 10$ min.) & n.s. & 0.0038 & $<0.0001$ & 0.0016 \\
\hline
\end{tabular}

Abbreviations: NMBA neuromuscular blocking agents, $M$ male, $F$ female, BMI body mass index, TIVA Total intravenous anaesthesia, BIS Bispectral Index, PACU Post anaesthetic care unit, muscle power throughout lower: male, NMBA+, short and long anaesthesia time ( $>120$ min) partial effect visible towerds lower muscle power: TIVA

the univariate analysis, NMBA usage exhibit the strongest statistic effect on both muscle power and $\mathrm{SpO}_{2}$ at all time points $(p<0.0001)$. Other factors also exhibited significant effects on muscle power (Table 3). Loss of postoperative muscle power for patients receiving and not receiving NMBAs was affected by female gender and TIVA; NMBA usage increased the individual effect of these factors (Tables 4 and 5). Thus independent significant factors within a stepwise regression model at each measurement point were NMBA usage $(p<0.0001)$, female gender $(p<0.0001)$ and TIVA $(p<0.027)$. The Fast Track score failed to predict significant muscle power loss in most patients.

\section{Postoperative pulse oximetric saturation}

Pulse oximetric saturation was decreased at all measurement points (Table 2). Within the univariate analysis, NMBA use had the most significant effect on postoperative $\mathrm{SpO}_{2}$; other factors also exerted effects (Table 6). Reduced postoperative muscle strength and decreased $\mathrm{SpO}_{2}$ indicates a certain correlation over the $2 \mathrm{~h}$ (Fig. 1). However, in patients not receiving NMBAs, there was no such correlation (Fig. 2).

\section{Discussion}

Fast track procedures in perioperative care have been established over the last decade even in high-risk patients. Quick recovery of muscular power is clearly essential for early mobilisation and overall outcome [27]. Safety standards as neuromuscular monitoring and standard operating procedures have led to a reduction in perioperative complications [28, 29]. Although we have maintained these safety standards, our data show a loss of postoperative muscle power after general anaesthesia, undetected by the Fast Track scoring in the PACU. There was also an associated reduced postoperative $\mathrm{SpO}_{2}$. Despite (uncalibrated) acceleromyographic neuromuscular monitoring (aNMM) being applied, ensuring a TOF Ratio $\geq 0.9$ before extubation, use of NMBAs has the biggest impact on postoperative muscle power. Uncalibrated a NMM has a negative predictive value of $40 \%$; i.e. we cannot predict recovery of muscle power in the majority of our study population. Calibration of the accelerometer as well as establishing a TOF Ratio of 1.0 before extubation improves the predictive value up to $97 \%$ (77\% uncalibrated) [8] but at some time cost. Thus, the overall cost of treatment increases.

Table 4 NMBA usage and additional detrimental factors contributing to a lack in postoperative muscle power (t-Test, $p$-Value)

\begin{tabular}{|c|c|c|c|c|c|c|c|c|}
\hline \multirow[t]{2}{*}{ Muscle power } & \multicolumn{4}{|c|}{ NMBA $-(n=268)$} & \multicolumn{4}{|c|}{$\mathrm{NMBA}+(n=347)$} \\
\hline & TO h & T0.5 h & T1 h & T2 h & TO h & T0.5 h & $\mathrm{T} 1 \mathrm{~h}$ & T2 h \\
\hline Gender (M/F) & 0.0031 & $<0.0001$ & $<0.0001$ & 0.0012 & $<0.0001$ & $<0.0001$ & $<0.0001$ & $<0.0001$ \\
\hline Age $(\geq 55)$ & n.s. & n.s. & 0.0433 & 0.0056 & n.s. & n.s. & 0.0433 & n.s. \\
\hline $\mathrm{BMI}(\geq 30)$ & n.s. & n.s. & n.s. & n.s. & n.s & n.s. & n.s. & n.s. \\
\hline TIVA/Balanced Anaesthesia & 0.0153 & 0.0139 & $<0.0001$ & 0.0014 & 0.0007 & $<0.0001$ & $<0.0001$ & 0.0038 \\
\hline Clorazepat ( $\geq 20$ mg) & 0.0210 & n.s. & n.s. & n.s. & n.s. & n.s. & n.s. & n.s. \\
\hline Anaesthesia time(>120 min) & n.s. & 0.0389 & n.s. & n.s. & 0.0446 & n.s. & n.s. & 0.0231 \\
\hline Fast Track score/PACU( $\geq 10$ min.) & n.s. & n.s. & n.s. & n.s. & n.s. & 0.0006 & $<0.0001$ & 0.0046 \\
\hline
\end{tabular}

Abbreviations: NMBA neuromuscular blocking agents, $M$ male, $F$ female, BMI body mass index, TIVA Total intravenous anaesthesia, BIS Bispectral Index, PACU Post anaesthetic care unit 
Table 5 NMBA usage and additional detrimental factors contributing to a lack in postoperative $\mathrm{SpO}_{2}$ (t-Test, $p$-Value)

\begin{tabular}{|c|c|c|c|c|c|c|c|c|}
\hline \multirow[t]{2}{*}{$\mathrm{SpO}_{2}$} & \multicolumn{4}{|c|}{ NMBA - $(n=268)$} & \multicolumn{4}{|c|}{$\mathrm{NMBA}+(n=347)$} \\
\hline & TO h & T0.5 h & $\mathrm{T} 1 \mathrm{~h}$ & $\mathrm{~T} 2 \mathrm{~h}$ & TO h & T0.5 h & $\mathrm{T} 1 \mathrm{~h}$ & $\mathrm{~T} 2 \mathrm{~h}$ \\
\hline Gender (M/F) & n.s. & n.s. & 0.0067 & 0.0078 & n.s. & n.s. & 0.0274 & 0.0049 \\
\hline Age $(\geq 55)$ & n.s. & n.s. & n.s. & 0.0056 & n.s. & n.s. & 0.0433 & n.s. \\
\hline BMI $(\geq 30)$ & n.s. & n.s. & n.s. & n.s. & n.s & n.s. & n.s. & n.s. \\
\hline TIVA/Balanced Anaesthesia & n.s. & n.s. & n.s. & 0.0014 & 0.0012 & 0.0002 & 0.0107 & 0.0488 \\
\hline Clorazepat ( $\geq 20$ mg) & n.s. & n.s. & n.s. & n.s. & n.s. & n.s. & n.s. & n.s. \\
\hline Anaesthesia time ( $\geq 120 \mathrm{~min})$ & n.s. & n.s. & 0.0121 & 0.0112 & n.s. & n.s. & n.s. & n.s. \\
\hline $\begin{array}{l}\text { Fast trackFast track oreAldrete } \\
\text { score in PACU }(\geq 10)\end{array}$ & n.s. & n.s. & n.s. & n.s. & n.s. & 0.0404 & 0.0016 & n.s. \\
\hline
\end{tabular}

Abbreviations: NMBA neuromuscular blocking agents, $M$ male, $F$ female, BMI body mass index, TIVA Total intravenous anaesthesia, BIS Bispectral Index, PACU Post anaesthetic care unit

Additionally, longer surgery times after only a single dose of a neuromuscular blocking agent do not themselves prevent residual neuromuscular block [10].

Controversy exists concerning the antagonisation after NMBA usage as a standard procedure, e.g. using neostigmine as detrimental side effects including bradycardia and prolongation of the QT interval, nausea and vomiting, and an increase in bronchial tone can occur [30]. The use of cyclodextrines (Suggamadex ${ }^{\circ}$ ) is an effective alternative with some blockers, but overall anaesthesia costs increase [31].

Omitting NMBA by using alternative airway devices e.g. the laryngeal mask airway (LMA) has still its limitations and is not appropriate in every case [32]. Additionally a complete eschewal of NMBA for orotracheal intubation is impracticable and harmful [33, 34].

Other factors contributing to a lack of postoperative muscle power can be identified. We have shown clear gender differences, partly explained by the gender bias in accelerometry which is not usually adjusted for [35]. Although NMBAs were administered according to ideal body weight, the different fat/muscle/body water proportion in females may alter drug distribution [36]. Gender specific drug variation has already been confirmed for some anaesthesia related drugs $[37,38]$.

Hypnotic drugs can have similar effects on pharyngeal muscle tone. Volatile anaesthetics reinforce neuromuscular block at hypnotic, but not subhypnotic, concentrations [39]. Propofol however has a negative impact on pharyngeal tone and postoperative oxygenation even at subhypnotic concentrations $[15,40]$. In contrast to the short term wash-out kinetics of most volatile anaesthetics, propofol has enduring effects on the basis of the specific elimination kinetics within the first 2 postoperative hours [41, 42], an effect enhanced with increasing age. An overall dosage reduction of propofol e.g. with supplemental remifentanil application seems reasonable.

Additionally, aging can possibly alter these effects mostly attributable to a decrease in hepatic metabolisation. This raises the question of whether current standards e.g. fast-track scores or TOF ratio of 0.9 before extubation are suitable for every patient. Under certain conditions these procedures fail or are inadequate. In particular, NMBA usage, female gender and TIVA can exhibit a potential effect in terms of muscle impairment resulting in an upper airway collapse, desaturation and

Table 6 Effects on postoperative pulse oximetric saturation (t-Test, $P$-value)

\begin{tabular}{|c|c|c|c|c|}
\hline & TO h & T0.5 h & $\mathrm{T} 1 \mathrm{~h}$ & $\mathrm{~T} 2 \mathrm{~h}$ \\
\hline Gender (M/F) & n.s. & n.s. & 0.0249 & 0.0033 \\
\hline Age ( $\geq 55)$ & n.s. & n.s. & n.s. & n.s. \\
\hline BMI $(\geq 30)$ & n.s. & n.s. & n.s. & n.s. \\
\hline NMBA (NMBA+/NMBA-) & $<0.0001$ & $<0.0001$ & $<0.0001$ & 0.0013 \\
\hline TIVA/Balanced Anaesthesia & n.s. & n.s. & n.s. & n.s. \\
\hline Clorazepat ( $\geq 20$ mg) & n.s. & n.s. & n.s. & n.s. \\
\hline Anaesthesia time( $\geq 120 \mathrm{~min})$ & 0.0134 & 0.0157 & 0.0014 & 0.0070 \\
\hline Fast Track score in PACU ( $\geq 10$ min.) & n.s. & n.s. & 0.0019 & 0.0269 \\
\hline
\end{tabular}

Abbreviations: NMBA neuromuscular blocking agents, $M$ male, $F$ female, BMI body mass index, TIVA Total intravenous anaesthesia, BIS Bispectral Index, PACU Post anaesthetic care unit

Pulse oximetric saturation troughout lower: NMBA+ short and long anaesthesia time (>120 min)

Partial effect visible towards lower pulse oximetric saturation: male, fast track score $<10$ 

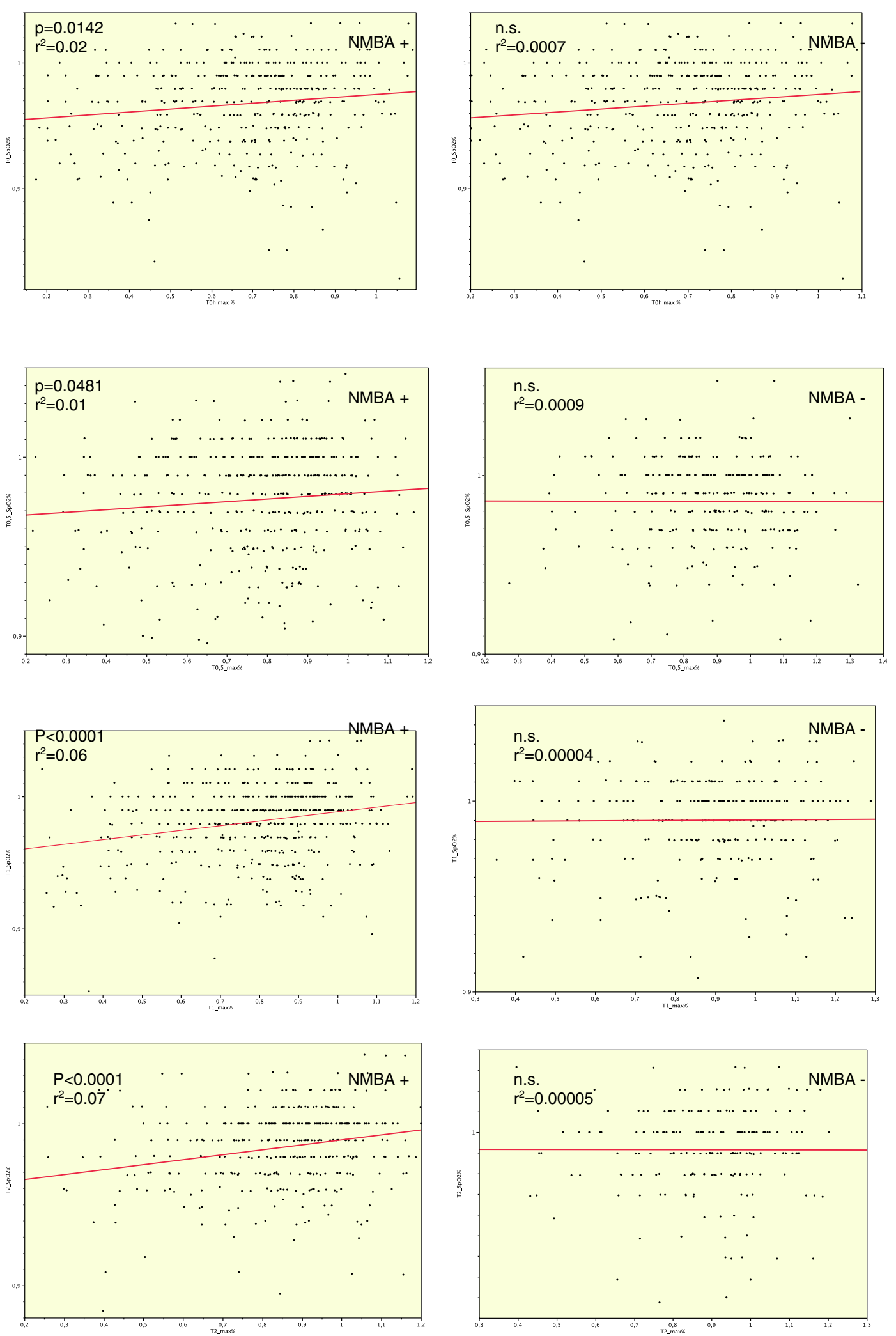

Fig. 2 NMBA+ vs. NMBA -/muscle power and pulse oximetric saturation. Simple regression analysis: Correlation of pulse oximetric Saturation and muscle power in terms of NMBA usage (+/-) y-axis = pulse oximetric saturation (percentage of preoperative baseline) $x$-axis = peak muscle power (percentage of preoperative baseline) 
contribute to major complications. In this regard our study setting

was not designed to reveal hard endpoints such as pneumonia, in-hospital mortality or myocardial infarction but rather to display possible interactions of both patient and anaesthesia related factors.

This could finally lead to an individualised risk stratification and anaesthesia management towards postoperative muscle power. In this context possible gender differences in both in pharmacodynamics and NMM as well as pharmacological interactions of TIVA and NMBA should be of further interest.

\section{Limitations}

Anyhow, our study has some limitations. The cohort design has no active randomization displaying daily routine and were only single centre collected. Hence our statements can merely partially generalized. Although the complete dataset has a homogenous distribution, the two main subcohorts (+NMBA/-NMBA) within our study population exhibited statistic significant differences. Nevertheless, in general these differences were small and statistic significance was mostly attributable to the large study population rather than clinical relevance. Despite that, a cohort bias cannot be completely excluded.

NMM was standardized and verified by our study nurses before extubation. Nevertheless this method has a potential bias. Additionally we applied an uncalibrated semiquantitative NMM which can exhibit a greater bias rather than a calibrated device.

Muscle power tests using the hand pressure device were potentially influenced by both patient vigilance and study nurse performance. In order to minimize interindividual bias we performed all measurements as a best of three attempt and analysed only the best attempt (at every time point) displayed as percentage of preoperative baseline measurement in each patient.

Our study was intended to identify possible risk factors rather than find major morbidity in minor surgery patients. We cannot completely exclude further drug interactions, as we did not measure plasma concentrations of the respective NMBA or hypnotics. Finally our findings may not be representative due to the single centre analysis but could be a starting point for future investigation of the interaction of single factors.

\section{Conclusion}

A TOF-Ratio of $>0.9$ does not prevent reasonable muscle power loss within the perioperative period which has a significant negative impact on pulsoximetric saturation. Additional independent detrimental factors were female gender and TIVA. Thus an overall reduction in NMBA usage even as a single dosage is reasonable.

\section{Abbreviations}

NMBA: Neuromuscular blocking agents; NMM: Neuromuscular monitoring; PACU: Post anaesthesia care unit; RNMB: Residual neuromuscular blockade; SOP: Standard operating procedure; TIVA: Total intravenous anaesthesia; TOF: Train of four

\section{Acknowledgements}

We thank Roger Fletcher (M.D.) for language revision.

\section{Funding}

Institutional resources only (University of Marburg- study fund).

\section{Availability of data and materials}

The datasets used and/or analysed during the current study available from the corresponding author on reasonable request.

\section{Authors' contributions}

Conception and design: TK, DK, BV, RB, TW, HW, MZ. Acquisition of data: DK, BV, MZ. Analysis and interpretation of data: TK, DK, BV, RB, TW, HW, MZ. Drafting the manuscript and revising it critically: TK, DK, BV, RB, TW, HW, MZ. All authors read the manuscript and have given their final approval of the version that is for publication.

\section{Ethics approval and consent to participate}

Ethics committee approval was obtained (University of Marburg, ref. no. AZ 176/ 09). Informed consent was obtained in every patient included. As a result of the study design no written consent was demanded by the Ethics committee.

\section{Consent for publication}

Not applicable

Competing interests

The authors declare that they have no competing interests.

\section{Publisher's Note}

Springer Nature remains neutral with regard to jurisdictional claims in published maps and institutional affiliations.

\section{Author details}

'Department of Anaesthesia and Intensive Care Medicine, University of Marburg, Baldinger Strasse, D-35033 Marburg, Germany. ${ }^{2}$ Department of Anaesthesia and Intensive Care Medicine, Clinique Bénigne Joly, 4 Allée Roger Renard, F-21240 Talant, France. ${ }^{3}$ Department of Anaesthesia, Intensive Care Medicine and Pain therapy, Kreisklinikum, Weidenauerstrasse 76, D-57076 Siegen, Germany.

Received: 3 January 2017 Accepted: 14 August 2017 Published online: 22 August 2017

\section{References}

1. Berg H, Roed J, Viby-Mogensen J, Mortensen CR, Engbaek J, Skovgaard LT, Krintel JJ. Residual neuromuscular block is a risk factor for postoperative pulmonary complications. Acta Anaesthesiol Scand. 1997 Oct;41(9):1095-103.

2. Bevan DR. Recovery from neuromuscular block and its assessment. Anesth Analg. 2000;90:S7-S13.

3. Beemer GH, Rozental P. Postoperative neuromuscular function. Anaesth Intensive Care. 1986;14:41-5.

4. Eriksson LI, Sundman E, Olsson R, Nilsson L, Witt H, Ekberg O. Functional assessment of the pharynx at rest and during swallowing in partially paralyzed humans. Simultaneous videomanometry and mechanomyography of awake human volunteers. Anesthesiology. 1997;87:1035-43.

5. Eikermann M, Vogt FM, Herbstreit F, Vahid-Dastgerdi M, Zenge MO, Ochterbeck C, de Greiff A, Peters J. The predisposition to inspiratory upper airway collapse during partial neuromuscular blockade. Am J Respir Crit Care Med. 2007;1(175):9-15.

6. Eikermann M, Blobner M, Groeben H, Rex C, Grote T, Neuhäuser M, Beiderlinden M, Peters J. Postoperative upper airway obstruction after recovery of the train of four ratio of the adductor pollicis muscle from neuromuscular blockade. Anesth Analg. 2006;102:937-42. 
7. Eikermann M, Groeben H, Hüsing J, Peter J. Accelerometry of adductor pollicis muscle predicts recovery of respiratory function from neuromuscular blockade. Anesthesiology. 2003;98:1333-7.

8. Capron F, Alla F, Hottier C, Meistelmann C, Fuchs-Buder T. Can acceleromyography detect low levels of residual paralysis? A probability approach to detect a mechanomyographic train-of-four ratio of 0.9 . Anesthesiology. 2004;100:1119-24.

9. Suzuki T, Fukano N, Kitajima O, Saeki S, Ogawa S. Normal- ization of acceleromyographic train-of-four ratio by baseline value for detecting residual neuromuscular block. Br J Anaesth. 2006;96:44-7.

10. Baillard C, Clec'h C, Catineau J, et al. Postoperative residual neuromuscular block: a survey of management. Br J Anaesth. 2005;95:622-6.

11. Debaene B, Plaud B, Dilly MP, Donati F. Residual paralysis in the PACU after a single intubating dose of non-depolarizing muscle relaxant with an intermediate duration of action. Anesthesiology. 2003;98:1042-8.

12. Soltesz S, Mencke T, Stunz M, Diefenbach C, Ziegeler S, Molter GP. Attenuation of rocuronium-induced neuromuscular block in patients receiving prednisolone. Acta Anaesthesiol Scand. 2009;53:443-8.

13. Eikermann M, Rasmuss LS. Improving the prediction of neuromuscular block. Acta Anaesthesiol Scand. 2009;53:423-4.

14. Eastwood PR, Szollosi I, Platt PR, Hillman DR. Collapsibility of the upper airway during anesthesia with isoflurane. Anesthesiology. 2002;97:786-93.

15. Eastwood PR, Platt PR, Shepherd K, Maddison K, Hillman DR. Collapsibility of the upper airway at different concentrations of propofol anesthesia. Anesthesiology. 2005;103:470-7.

16. Kopman AF, Yee PS, Neuman GG. Correlation of the train-of-four fade ratio with clinical signs and symptoms of residual curarization in awake volunteers. Anesthesiology. 1997;86:765-71.

17. Eriksson LI, Sato M, Severinghaus JW. Effect of a vecuronium induced partial neuromuscular block on hypoxic ventilatory response. Anesthesiology. 1993;78:693-9

18. Sundman E, Witt H, Olsson R, Ekberg O, Kuylenstierna R, Eriksson LI. The incidence and mechanisms of pharyngeal and upper esophageal dysfunction in partially paralyzed humans. Pharyngeal videoradiography and simultaneous manometry after atracurium. Anesthesiology. 2000;92:977-84.

19. White PF, Song D. New criteria for fast-tracking after outpatient anesthesia: a comparison with the modified Aldrete's scoring system. Anesth Analg. 1999:88:1069-72.

20. Baumüller E, Schaller SJ, Chiquito Lama Y, Frick CG, Bauhofer T, Blobner M. Postoperative impairment of motor function at train-of-four ratio $\geq 0.9$ cannot be improved by sugammadex (1 mg kg-1). Br J Anaesth. 2015;114(5):785-93.

21. Hüppe M, Kemter A, Schmidtke C, Klotz KF. Postoperative complaints : gender differences in expectations, prevalence and appraisal. Anaesthesist. 2013;62(7):528-36.

22. Oosting E, Hoogeboom TJ, Dronkers JJ, Visser M, Akkermans RP, van Meeteren NLU. The influence of muscle weakness on the association between obesity and inpatient recovery from Total hip Arthroplasty. J Arthroplast. 2017 Jun;32(6):1918-22.

23. Zoremba M, Aust H, Eberhart L, Braunecker S, Wulf H. Comparison between intubation and the laryngeal mask airway in moderately obese adults. Acta Anaesth Scand. 2009;53(4):436-42.

24. Zoremba M, Kalmus G, Steinfeldt T, Wulf H, Dette F. Respiratory impairment in the obese following general anesthesia - impact of anaesthesia and patient related factors. J Anesthe Clinic Res. 2010;1:108.

25. Murphy GS1, Szokol JW, Marymont JH, Franklin M, Avram MJ, Vender JS. Residual paralysis at the time of tracheal extubation. Anesth Analg. 2005 Jun;100(6):1840-5.

26. Arain SR1, Kern S, Ficke DJ, Ebert TJ. Variability of duration of action of neuromuscular-blocking drugs in elderly patients. Acta Anaesthesiol Scand. 2005 Mar;49(3):312-5.

27. ERAS compliance group. The impact of enhanced recovery protocol compliance on elective colorectal cancer resection: results from an international register. Ann Surg. 2015;261:1153-9. doi:10.1097/SLA.0000000000001029.

28. Eichhorn JH. Practical current issues in perioperative patient safety. Can J Anesth. 2013;60:111-8

29. Wacker J, Staender S. The role oft he anesthesiologist in perioperative patient safety. Curr Opin Anaesthesiol. 2014;27:649-56.

30. Srivastava A, Hunter JM. Reversal of neuromuscular block. Br J Anaesth. 2009;103:115-29.

31. Caldwell JE, Miller RD. Clinical implications of sugammadex. Anaesthesia. 2009;64(Suppl 1):66-72.
32. Verghese C, Brimacombe JR. Survey of laryngeal mask airway usage in 11,910 patients: safety and efficiacy for conventional and nonconventional usage. Anaesth Analg. 1996;82:129-33.

33. Mecke T, Echternach $M$, Kleinschmidt S, Lux P, Barth V, Plinkert PK, FuchsBuder T. Laryngeal morbidity and quality of tracheal intubation: a randomized controlled trial. Anesthesiology. 2003;98:1049-56.

34. Combes $X$, Andriamifidy L, Duresne E, Suen P, Sauvat S, Scherrer E, Feiss $P$, Marty J, Duvaldestin P. Comparison of two induction regimes using or not using muscle relaxant: impact on postoperative upper airway discomfort. Br J Anaesth. 2007:99:276-81.

35. Heier T, Feiner JR, Wright PM, Ward T, Caldwell JE. Sex related differences in the relationship between acceleromyographic adductor pollicis train-of-four ratio and clinical manifestations of residual neuromuscular block: a study in healty volunteers during near steady-state infusion of mivacurium. $\mathrm{Br}$ J Anaesth. 2012:108:444-51.

36. Ritz P, Vol S, Berrut G, Tack I, Arnaud MJ, Tichet J. Influence of gender and body composition on hydration and body water spaces. Clin Nutr. 2008;27:740-6.

37. Ueno K. Gender differences in pharmacokinetics of anesthetics. Masui. 2009:58:51-8.

38. Adamus M, Garbrhelik T, Mark O. Influence of gender on the course of neuromuscular block following a single bolus dose of cisatracurium or rocuronium. Eur J Anaesthesiol. 2008:25:589-95.

39. Fuchs-Bruder T, Eikermann M. Residual neuromuscular blockades. Clinical consequences, frequency and avoiding strategies. Anaesthesist. 2006;55:7-16.

40. Juvin P, Vadam C, Malek L, Dupont H, Marmuse J-P, Desmonts J-M. Postoperative recovery after desflurane, propofol, or isoflurane anesthesia among morbidly obese patients: a prospective, randomized study. Anesth Analg. 2000;91:714-9.

41. Juvin P, Servin F, Giraud O, Desmonts JM. Emergence of elderly patients from prolonged desflurane, isoflurane, or propofol anesthesia. Anesth Analg. 1997:85:647-51.

42. Herminghaus A, Löser S, Wilhelm W. Anesthesia for geriatric patients. Anaesthesist. 2012:61:363-74.

\section{Submit your next manuscript to BioMed Central and we will help you at every step:}

- We accept pre-submission inquiries

- Our selector tool helps you to find the most relevant journal

- We provide round the clock customer support

- Convenient online submission

- Thorough peer review

- Inclusion in PubMed and all major indexing services

- Maximum visibility for your research

Submit your manuscript at www.biomedcentral.com/submit
) Biomed Central 